\title{
Fabrication and characterization of dexibuprofen nanocrystals using microchannel fluidic rector
}

This article was published in the following Dove Press journal:

Drug Design, Development and Therapy

\author{
Jahangir Khan ${ }^{1-3}$ \\ Sajid Bashir' \\ Muhammad Asif Khan ${ }^{4}$ \\ Mohammad Amin \\ Mohammad $^{3}$ \\ Mohammad Isreb ${ }^{3}$ \\ 'Department of Pharmacy, Faculty \\ of Pharmacy, University of Sargodha, \\ Sargodha, Pakistan; ${ }^{2}$ Department of \\ Pharmacy, University of Malakand, \\ Dīr, Khyber Pakhtunkhwa, Pakistan; \\ ${ }^{3}$ School of Pharmacy, Institute of Life \\ Science Research, School of Pharmacy, \\ University of Bradford, Bradford, UK; \\ ${ }^{4}$ Department of Pharmacy, Sarhad \\ University Peshawar, Peshawar, \\ Pakistan
}

Purpose: Dexibuprofen is an enantiomer of ibuprofen with low bioavailability which results from its hydrophobic nature. Nanosuspensions have developed a podium to solve the in vitro dissolution problem that frequently occurs in current research.

Materials and methods: The drug and polymer solutions were mixed in a microchannel fluid reactor and the successive embryonic nanosuspension was decanted into a vial having the polymer solution. The impact of different process and formulation parameters including inlet angle, antisolvent and solvent flow rate(s), mixing time, drug concentration, polymer type and concentration was evaluated.

Results and discussion: Stable dexibuprofen nanocrystals with a particle size of $45 \pm 3.0 \mathrm{~nm}$ and polydispersity index of $0.19 \pm 0.06$ were obtained. Differential scanning calorimetry and powder X-ray diffraction confirmed the crystallinity. The key parameters observed were inlet angle $10^{\circ}$, antisolvent to solvent volume of $2.0 / 0.5 \mathrm{~mL} / \mathrm{min}, 60$ minutes mixing with 5 minutes sonication, Poloxamer- 407 with a concentration of $0.5 \% \mathrm{w} / \mathrm{v}$ and drug concentration $(5 \mathrm{mg} / \mathrm{mm})$. The 60-day stability studies revealed that the nanocrystals were stable at $4{ }^{\circ} \mathrm{C}$ and $25^{\circ} \mathrm{C}$. The scanning electron microscopy and transmission electron microscopy images showed crystalline morphology with a homogeneous distribution.

Conclusion: Stable dexibuprofen nanocrystals with retentive distinctive characteristics and having marked dissolution rate compared to raw and marketed formulations were efficiently fabricated. In future perspectives, these nanocrystals could be converted to solid dosage form and the process can be industrialized by chemical engineering approach.

Keywords: nanocrystal, dexibuprofen, microchannel fluidic reactor, process and formulation parameters

\section{Introduction}

The issue of poor water solubility for a list of drug candidates has become a hard challenge for the drug delivery scientists both from academia and research and development sectors. ${ }^{1}$ As per the scientist reports, nearly $70 \%$ of the applicant drugs in development phase and $40 \%$ of marketed APIs available as oral dosage forms are practically insoluble in water. ${ }^{2}$ The issue of poor water solubility would lead to erratic bioavailability and, consequently, unwanted toxic effects. ${ }^{3}$ Drug delivery scientists, by their continuous struggle, have developed and designed a range of strategies to boost the solubility and dissolution of medicines in aqueous media, including solid dispersions, solubilization, emulsions, micronization and so on. ${ }^{4}$ However, these approaches have limited applications because of the production of ionizable groups, stability issues and limited improvement in solubility. ${ }^{5}$ In addition the added solvents residues, enhances the solubility that can lead to potential toxicity and other unwanted
Correspondence: Jahangir Khan

Department of Pharmacy, University

of Malakand, Chakdara I8800, Khyber

Pakhtunkhwa Pakistan

Tel +92333 37l 495।

Email jahangirkhan222@gmail.com (c) (1) () 2018 Khan et al. This work is published and licensed by Dove Medical Press Limited. The full terms of this license are available at https://www.dovepress.com/terms.php cc. hereby accept the Terms. Non-commercial uses of the work are permitted without any further permission from Dove Medical Press Limited, provided the work is property attributed. For permission for commercial use of this work, please see paragraphs 4.2 and 5 of our Terms (htpps//www.dovepress.com/terms.php). 
side effects. It is, therefore, the utmost need to develop alternative approaches to enhance the solubility of plethora of drug compounds. ${ }^{6}$

It has become evident from the present literature that nanosuspensions have developed a podium to solve the in vitro dissolution problem that frequently occurs in current research. ${ }^{7}$ Nanocrystal can be created by bottom-up and top-down methods. ${ }^{8}$ In top-down methods, the size reduction occurs by mechanical forces and attrition forces. However, some of the issues associated with top-down methods include long processing time, broad particle size distribution and contamination. ${ }^{9}$ Bottom-up method involves antisolvent precipitation in which the significant footstep is nucleation. ${ }^{10}$ The issues associated with the bottom-up methods are uncontrolled particle growth through Ostwald ripening and changes in particle attributes with partial or complete conversion to amorphous state, which can potentially cause phase transition and stability issues. ${ }^{9}{ }^{11}$ It is of paramount importance for crystalline nanoparticles to be fabricated because it causes long-term stability. ${ }^{7}$

Dexibuprofen is the active form of ibuprofen in vitro and in vivo. ${ }^{12}$ It is rapid acting and used in a decreased quantity as compared to its racemic mixture. ${ }^{13}$ It is indicated for dental pain, dysmenorrhea, postoperative pain and headache. ${ }^{14}$ It is a Biopharmaceutics Classification System class II drug. Its aqueous solubility is $51 \mu \mathrm{g} / \mathrm{mL}$ as compared to ibuprofen $(21 \mu \mathrm{g} / \mathrm{mL})$, and its bioavailability is low in the gastric environment, which can be enhanced by increasing its aqueous solubility. ${ }^{15}$

The basic principle of antisolvent precipitation with syringe pump (APSP) is the addition of drug molecules from organic phase through a syringe pump into aqueous polymer phase and, consequently, nucleation and particle formation occur while the microchannel fluidic reactor (MCFR) has a small channel in which the liquid behavior is in contrast to the conventional flow theory, that is, the liquids follow laminar flow pattern without turbulence and mixing of liquid occurs due to diffusion of molecules across the liquid interface. ${ }^{16} \mathrm{MCFR}$ is a novel advanced low-energy bottom-up approach, which is different from APSP. Basically, in these approaches, the important step is micromixing of antisolvent aqueous polymer solution and organic solvent drug solution, which controls the nucleation, crystal size and attributes of the nanocrystal. In the APSP method, only the solvent drug solution is controlled, while in MCFR, both the solutions (antisolvent and solvent solutions) are controlled, leading to more control on nucleation, particle size, size distribution, stability and characteristics of the nanocrystals.
This study aimed to evaluate the modified MCFR process and produce nanocrystals of dexibuprofen through the modified MCFR method. The hydrocortisone nanoparticles reported by Ali et al ${ }^{17}$ were produced by MCFR with a particle size above $200 \mathrm{~nm}$. In that method, the crystallized nanoparticles were mixed with the buffer solution composed of polymers using stirring and sonication. However, in this new method, we used a polymeric solution during mixing of the drug solution in MCFR as well as after processing the nanosuspension. Crystallization of the drug in plain water and in polymeric medium are substantially different from each other. In polymeric medium, the nucleation and particle size are controlled by the polymer molecules, which results in low particle size and homogenous size distribution. ${ }^{18}$ In the current project, the special characteristics of nanocrystals were investigated by executing different assessments which included the particle size, zeta potential, powder X-ray diffraction (PXRD), differential scanning calorimetry (DSC), scanning electron microscopy (SEM), transmission electron microscopy (TEM), stability studies and in vitro dissolution.

\section{Materials and methods}

The following were the chemicals and the manufacturers from where they were obtained: dexibuprofen (batch no C102-150100M; Hubei Biocause Helen Pharmaceutical, Hubei, China), Poloxamer-407 (batch no BCBK50056; Sigma-Aldrich, Dorset, UK), polyvinylpyrrolidon-K30 (batch no 08297052 G0; BASF, Ludwigshafen, Germany), hydroxypropyl methyl cellulose (HPMC) viscosity $15 \mathrm{cps}$ (batch no 8028213; Shin-etsu, Tokyo, Japan). Laboratory distilled water was obtained from the research laboratory of Bradford University.

\section{Preparation of dexibuprofen nanosuspension}

The current method is a modification of the previously published method of Ali et al. ${ }^{17}$ Dexibuprofen dissolved in ethanol $(5 \mathrm{mg} / \mathrm{mL})$ and polymers dissolved in aqueous phase were introduced into MCFR (inlet angle $10^{\circ}$ with internal diameter of $0.5 \mathrm{~mm}$ ) at a flow rate $0.5: 2.0 \mathrm{~mL} / \mathrm{min}$, respectively. Then, the emergent nanosuspension was poured into a vial having aqueous polymer solution and stirred for 60 minutes (Figure 1). At the end, the nanosuspension was sonicated for 5 minutes with $100 \mathrm{~W}$ ultrasonication (P1200; Crest Ultrasonic, Ewing Township, NJ, USA). ${ }^{19}$ The impact of five important process parameters including 1) polymer type and its concentration, 2) inlet angle, 3) solvent and antisolvent 
flow rates, 4) drug concentration and 5) stirring time with and without ultrasonication was assessed at three levels.

\section{Particle size and zeta potential measurements}

Particle size measurements of the produced nanosuspension were determined through photon correlation spectroscopy (Zetasizer ${ }^{\mathbb{B}}$ NanoS; Malvern Instruments, Malvern, UK). All the samples were subjected to particle size analysis without further dilution. The average particle size diameter (Z.Ave) and the polydispersity index (PDI) were determined from three measurements. Additionally, the zeta potential calculations of the produced nanoparticles were carried out using the Malvern Zetasizer. The clear disposable zeta cells were used for zeta potential measurements. The samples were analyzed in triplicate.

\section{SEM}

The morphology of unprocessed dexibuprofen was evaluated using SEM (Quanta 400; FEI, Cambridge, UK). The images were taken at different magnifications levels. Gold coating of the dexibuprofen particles using sputter coater was carried out to obtain clear images.

\section{TEM}

The external morphology of the produced nanosuspension was characterized by TEM (JEM-1200EX; JEOL, Tokyo, Japan) performed at $100 \mathrm{kV}$. Nanosuspension drop was poured on copper grid surface and dried at ambient temperature; then, magnesium uranyl acetate solution was applied as a $2 \%$ aqueous solution for negative staining.

\section{DSC analysis}

Thermal characteristics of the processed and unprocessed dexibuprofen were assessed using DSC (Discovery; TA Instrument, New Castle, DE, USA). The DSC instrument was calibrated with indium $99 \%$ and zinc having melting points $156.6^{\circ} \mathrm{C}$ and $419.5^{\circ} \mathrm{C}$, respectively. Under nitrogen atmosphere, the scanning rate of $10^{\circ} \mathrm{C} / \mathrm{min}$ was used for both raw and nanocrystals. The scan was performed at temperature ranging from $0^{\circ} \mathrm{C}$ to $100^{\circ} \mathrm{C}$. All the samples were analyzed in triplicate.

\section{X-ray powder diffraction analysis}

The X-ray powder diffraction of raw and produced nanocrystals was carried out with D5000 diffractometer (Siemens, Munich, Germany) consuming $\mathrm{Cu}$ Ka radiation ( $X=1.5418$ A). The samples were measured with the angle range of $5^{\circ}-50^{\circ}$, step size of $0.05^{\circ}$, count time of 3 seconds per step, rotation during analysis $30 \mathrm{rpm}$ and the generator fixed at $40 \mathrm{kV}$ and $30 \mathrm{~mA}$.

\section{Stability studies}

Dexibuprofen nanosuspensions were assessed for their chemical stability at regular time intervals in 1 week (day 0 , day 1 , day 3 , day 4 , day 5 , day 6 , day 7 ) and the $\%$ of drug content

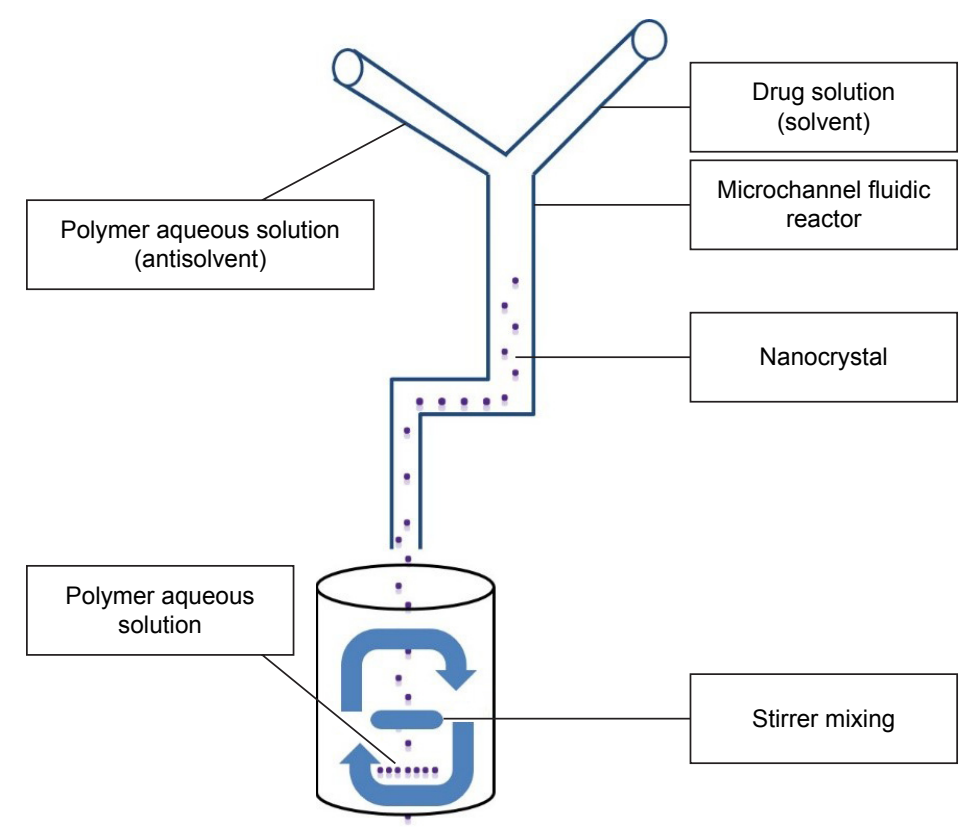

Figure I Schematic presentation of fabrication of dexibuprofen nanocrystal through MCFR. Abbreviation: MCFR, microchannel fluidic reactor. 
was evaluated with UV spectrophotometer (V-630; JASCO) at $222 \mathrm{~nm}$ as per the method reported previously. ${ }^{20}$ Moreover, physical stability study of the produced dexibuprofen nanosuspension was carried out at $25^{\circ} \mathrm{C}$ and $4^{\circ} \mathrm{C}$ for 60 days. The growth of the particles was monitored by measuring the particle size and PDI values at regular time intervals.

\section{In vitro dissolution}

The dissolution rate of the produced dexibuprofen nanocrystals was compared with those of raw and marketed formulations. The dissolution study was carried out using USP XXIV rotating paddle method. The sample was placed in dissolution vessels containing $900 \mathrm{~mL}$ phosphate buffer, $\mathrm{pH} 7.2$, maintained at $37^{\circ} \mathrm{C} \pm 0.5^{\circ} \mathrm{C}$ with a stirring speed of $100 \mathrm{rpm}$, which has been reported for nanosuspension. ${ }^{20,21}$ The samples were collected after 5, 10, 15, 20, 25, 30, 40, 50, and 60 minutes through a filter (Millex ${ }^{\circledR} \mathrm{GP}$; IRL) with a pore size of $0.22 \mu \mathrm{m}$ and were substituted with equal amount of fresh phosphate buffer solution. The samples were assessed on UV spectrophotometer (V-630; JASCO) at $222 \mathrm{~nm}$.

\section{Statistical analysis}

Statistical analysis of the experimentally collected data was done by SPSS 18 (SPSS Inc., Chicago, IL, USA). The data for all drugs were collected in triplicate. The data presented here are as mean $\pm \mathrm{SD}$. One-way analysis of variance test $(P<0.05)$ and least significant difference test were used.

\section{Results and discussion Impact of process conditions on the particle size of dexibuprofen nanoparticles}

This is a low-energy method which can produce stable drug nanocrystals. However, process optimization is important to be taken under consideration. Interestingly, a variation in particle size of the dexibuprofen was observed while changing the parameters. The impact of three levels of these parameters on the particle size is described below.

\section{Evaluation of polymers}

The effect of polymer type and concentration on the particle size of dexibuprofen nanocrystals was assessed (Figure 2). Poloxamer-407, PVP-K30 and HPMC-15cps were tested in single and combination forms at various concentrations. Poloxamer-407 $(0.5 \% \mathrm{w} / \mathrm{v})$ was found to be the most suitable polymer, and the nanocrystal attained a size of $45 \pm 3.0 \mathrm{~nm}$ with PDI of $0.19 \pm 0.06$. Particle size distribution is presented in Figure 3.

\section{Effect of flow rate of antisolvent and solvent}

Antisolvent volume variable and solvent volume constant

Antisolvent and solvent flow rate was assessed and it was observed that it had a dominant effect on nanocrystal size. The nanocrystal of smaller sizes was obtained while changing the antisolvent volume and keeping the drug solution constant.

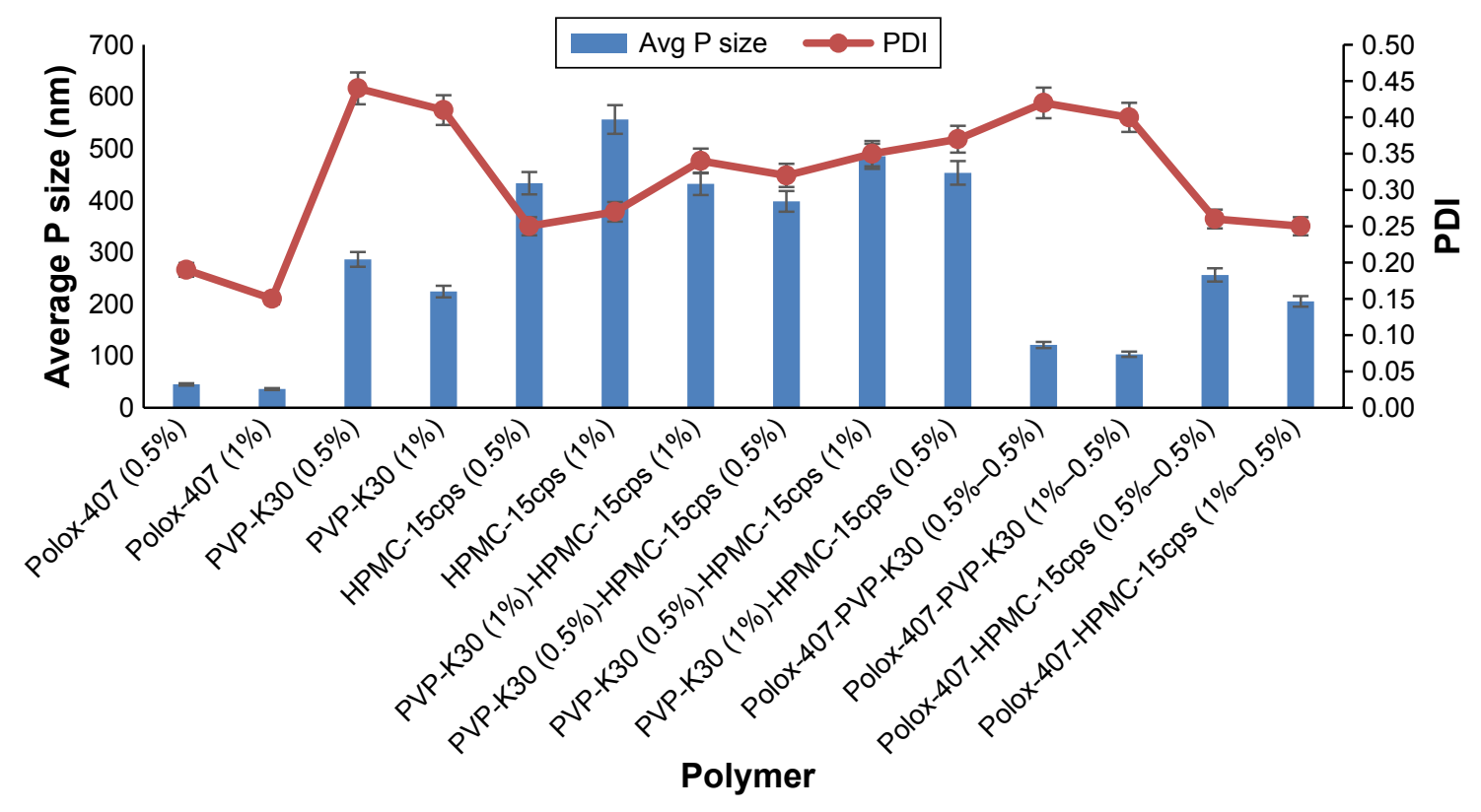

Figure 2 Effect of polymer type and its concentration on dexibuprofen nanocrystals.

Abbreviations: HPMC-15cps, hydroxypropyl methyl cellulose 15cps; PDI, polydispersity index; Polox-407, Poloxamer-407; PVP-K30, polyvinyl pyrrolidone k30. 


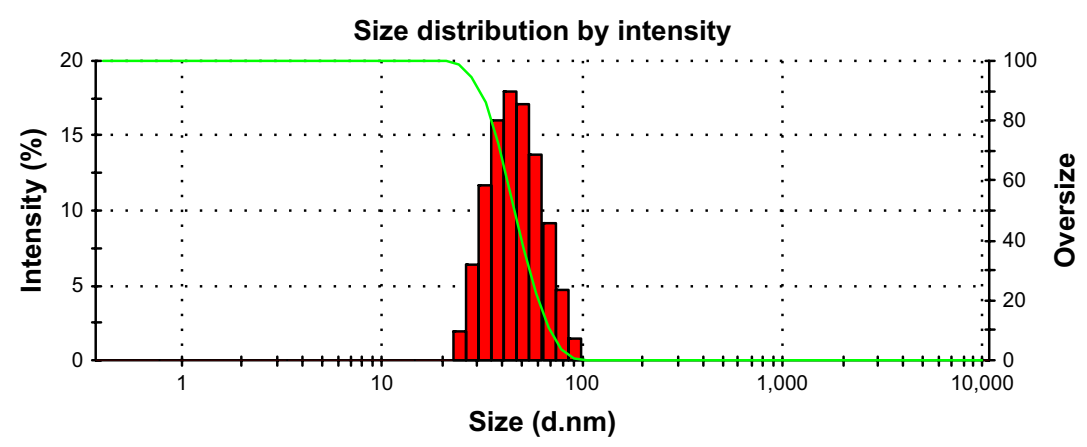

Figure 3 Particle size distribution of dexibuprofen nanoparticle (Poloxamer-407 [0.5\%]).

The nanoparticle size achieved at 2.0/0.5 mL/min was $45 \pm 3.0$ $\mathrm{nm}$ with a PDI of $0.19 \pm 0.06$ (Table 1 ). The relatively smaller particle sizes obtained are attributed to two reasons. The first one is the perfect mixing of the drug solution with the antisolvent solution because the antisolvent solution volume is high compared to the drug solution. ${ }^{22}$ The second one is the higher supersaturation level achieved in beginning due to less drug solution and antisolvent concentration, which decreases the solute concentration on the nuclei surfaces. ${ }^{23}$

\section{Antisolvent volume constant and solvent volume variable}

It was observed that keeping the antisolvent solution constant and increasing the volume of drug solution result in larger particles. The maximum size obtained at 2.0/2.0 $\mathrm{mL} / \mathrm{min}$ was $803 \pm 3.0 \mathrm{~nm}$ with a PDI of $0.57 \pm 0.19$ (Table 1). This

Table I Impact of process conditions on dexibuprofen nanoparticle size $(n=3)$

\begin{tabular}{|c|c|c|c|c|c|}
\hline \multicolumn{4}{|c|}{ Input variable } & \multicolumn{2}{|c|}{ Output variable } \\
\hline $\begin{array}{l}\text { Antisolvent } \\
\text { flow rate } \\
\text { (mL/min) }\end{array}$ & $\begin{array}{l}\text { Solvent } \\
\text { flow rate } \\
(\mathrm{mL} / \mathrm{min})\end{array}$ & $\begin{array}{l}\text { Drug } \\
\text { concentration } \\
(\mathrm{mg} / \mathrm{mL})\end{array}$ & $\begin{array}{l}\text { Inlet } \\
\text { angle }\end{array}$ & $\begin{array}{l}\text { Avg P } \\
\text { size } \pm S D \\
(\mathbf{n m})\end{array}$ & $\mathbf{P D I} \pm \mathbf{S D}$ \\
\hline 0.5 & 0.5 & 5 & 10 & $267 \pm 3.0$ & $0.36 \pm 0.17$ \\
\hline 1.0 & 0.5 & 5 & $10^{\circ}$ & $192 \pm 4.0$ & $0.34 \pm 0.09$ \\
\hline 1.5 & 0.5 & 5 & $10^{\circ}$ & $107 \pm 4.0$ & $0.28 \pm 0.10$ \\
\hline 2.0 & 0.5 & 5 & $10^{\circ}$ & $45 \pm 3.0$ & $0.19 \pm 0.06$ \\
\hline 2.0 & 1.0 & 5 & $10^{\circ}$ & $218 \pm 4.0$ & $0.34 \pm 0.14$ \\
\hline 2.0 & 1.5 & 5 & $10^{\circ}$ & $397 \pm 4.0$ & $0.39 \pm 0.17$ \\
\hline 2.0 & 2.0 & 5 & $10^{\circ}$ & $803 \pm 3.0$ & $0.57 \pm 0.19$ \\
\hline 0.5 & 0.5 & 5 & $10^{\circ}$ & $267 \pm 3.0$ & $0.36 \pm 0.17$ \\
\hline 1.0 & 1.0 & 5 & $10^{\circ}$ & $404 \pm 2.0$ & $0.39 \pm 0.18$ \\
\hline 1.5 & 1.5 & 5 & $10^{\circ}$ & $573 \pm 4.0$ & $0.43 \pm 0.22$ \\
\hline 2.0 & 2.0 & 5 & $10^{\circ}$ & $803 \pm 3.0$ & $0.57 \pm 0.19$ \\
\hline 2.0 & 0.5 & 10 & $10^{\circ}$ & $336 \pm 5.0$ & $0.37 \pm 0.07$ \\
\hline 2.0 & 0.5 & 15 & $10^{\circ}$ & $920 \pm 4.0$ & $0.39 \pm 0.08$ \\
\hline 2.0 & 0.5 & 5 & $25^{\circ}$ & $62 \pm 3.0$ & $0.22 \pm 0.09$ \\
\hline 2.0 & 0.5 & 5 & $50^{\circ}$ & $86 \pm 5.0$ & $0.34 \pm 0.10$ \\
\hline
\end{tabular}

Abbreviation: PDI, polydispersity index. effect is attributed to increase in drug concentration which inflates the solute fixation on the surface of framed nuclei and, thus, encourages molecular growth and produces bigger crystals. ${ }^{23}$

\section{Equal volume of antisolvent and solvent}

At equal ratios of both solutions, it was observed that higher stream rate $(2.0 / 2.0 \mathrm{~mL} / \mathrm{min})$ resulted in larger particle sizes $(803 \pm 3.0 \mathrm{~nm}$ with a PDI of $0.57 \pm 0.19$; Table 1$)$. The higher particle sizes obtained at higher stream rate of both solutions are due to inadequate blending of the drug solution with the antisolvent solution as the dwelling time in MCFR is very short; so, inadequate diffusion takes place ${ }^{24}$ and it may produce a non-uniform region supersaturation, subsequently producing bigger particles with more extensive size dispersion. ${ }^{17}$

\section{Drug concentration effect}

The drug concentration effect was evaluated and it was observed that larger particles sizes were obtained at higher concentrations (Table 1). Principally, higher concentration crops the growth of crystal through condensation and coagulation phenomenon. Moreover, at higher concentrations, the viscosity of the drug solution is high, which decreases mutual diffusion of antisolvent and solvent solutions with consequent creation of non-uniform supersaturation that ultimately produces larger particles through agglomeration or crystal growth. ${ }^{25}$ Furthermore, $\mathrm{BaSO}_{4}$ and prednisolone nanoparticles in MCFR have been produced with the same effect. ${ }^{17,22}$

\section{Inlet angle of MCFR}

Three different inlet angles were investigated for their effect on particle size of the dexibuprofen nanoparticles. The nanoparticles produced by angle $50^{\circ}$ were little a bit larger with slightly broader distribution as compared to those at angles 
$10^{\circ}$ and $25^{\circ}$ (Table 1). It is thought that Keener delta edges $\left(10^{\circ}\right.$ and $\left.25^{\circ}\right)$ have sharper channel edges which permit the two liquid streams to meet and then stream down the outlet without creating any interruption to either liquid stream, ${ }^{26}$ while at an angle of $50^{\circ}$, the liquid streams encounter a more even level creating further disturbance of the meeting liquid streams while forwarding to the vent.

\section{Effect of mixing time}

The effect of mixing time on nanosuspension was evaluated and it was observed that 60 minutes mixing produced nanoparticles with smaller sizes as compared to 30 minutes mixing (Figure 4). Following mixing, the produced nanosuspensions were sonicated with $100 \mathrm{~W}$ ultrasonication (P1200) for 5 minutes, which further reduced the size and PDI. Principally, high stirring rate and efficient mixing can potentially produce high level of micromixing, supersaturation and rapid nucleation, and consequently, nanocrystals with relative smaller particle size are produced. ${ }^{27}$

\section{Stability studies}

Stability of the nanocrystal is very significant because nanonization enhances surface area with increase in surface free energy, and consequently, stability of nanoparticle is greatly affected. Moreover, little bit of high solubility of the drugs at higher temperature leads to lower supersaturation level with subsequent growth of nanoparticles through Ostwald ripening. ${ }^{28}$ The van der Waals forces among the nanocrystals lead to agglomeration and, consequentially, weaken the nanosuspensions. The zeta potential value obtained was $-22.1 \pm 2.2 \mathrm{mV}$, and the literature reported value for nanosuspensions is $\pm 20 \mathrm{mV} .{ }^{29,30}$ The chemical stability of the produced nanosuspensions was evaluated for 1 week as per the method reported previously. ${ }^{20}$ The $\%$ of the drug content of dexibuprofen nanosuspension stored for 7 days was $96.9 \% \pm 2.6 \%$. No sign of degradation was observed. Moreover, the produced nanosuspensions were assessed for their physical stability at $4^{\circ} \mathrm{C}$ and $25^{\circ} \mathrm{C}$ for a period of 60 days. It was observed that the nanosuspensions stored at both temperatures were stable and no significant growth occurred (Figures 5 and 6). The 2-month stability data indicate homogenous distribution of nanoparticles and as per Deng et al, ${ }^{34}$ homogenous distribution prevents Ostwald ripening. Moreover, regarding nanosuspension stability, Freitas and Müller recommended that it should be kept in fridge $\left(2^{\circ} \mathrm{C}-8^{\circ} \mathrm{C}\right)$ to retain its particle size. ${ }^{31}$

\section{Thermal and X-ray analysis}

The crystallinity of the nanocrystals was assessed and compared with that of the raw counterparts using DSC and PXRD. These studies confirmed that the nanoparticles were crystalline in nature. The raw drug and the produced nanoparticles had sharp melting endotherm. A reduction in melting point of nanocrystals was observed related to the raw drugs. The melting point of raw dexibuprofen was $53.0^{\circ} \mathrm{C}$, while that of dexibuprofen nanocrystal was $50.0^{\circ} \mathrm{C}$ (Figure 7). This is because of the small particle size and lower packing density of the nanocrystals lattice compared to those of raw particles. ${ }^{32}$ Basically, peak intensity shifted to lower level because of minor angle reflection by the nanocrystals. Furthermore, due to sizing effects, the peak for the nanocrystals was also found to be little broadened compared to the raw drug. The PXRD study also confirmed the crystalline characteristics of the nanoparticles. The PXRD diffractograms of the raw dexibuprofen was found to have

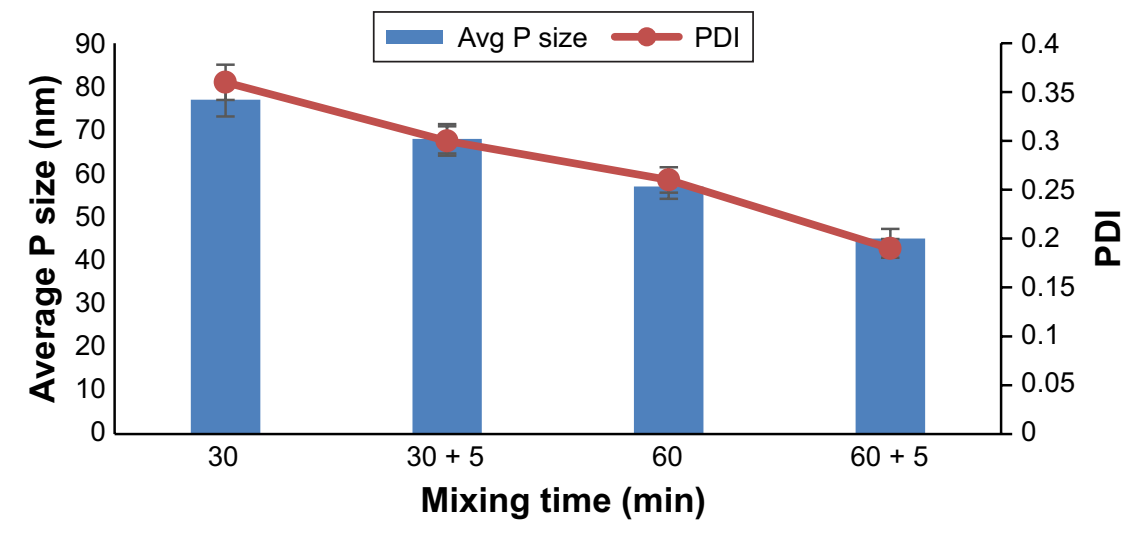

Figure 4 Effect of mixing time on dexibuprofen nanoparticle size. Abbreviation: PDI, polydispersity index. 


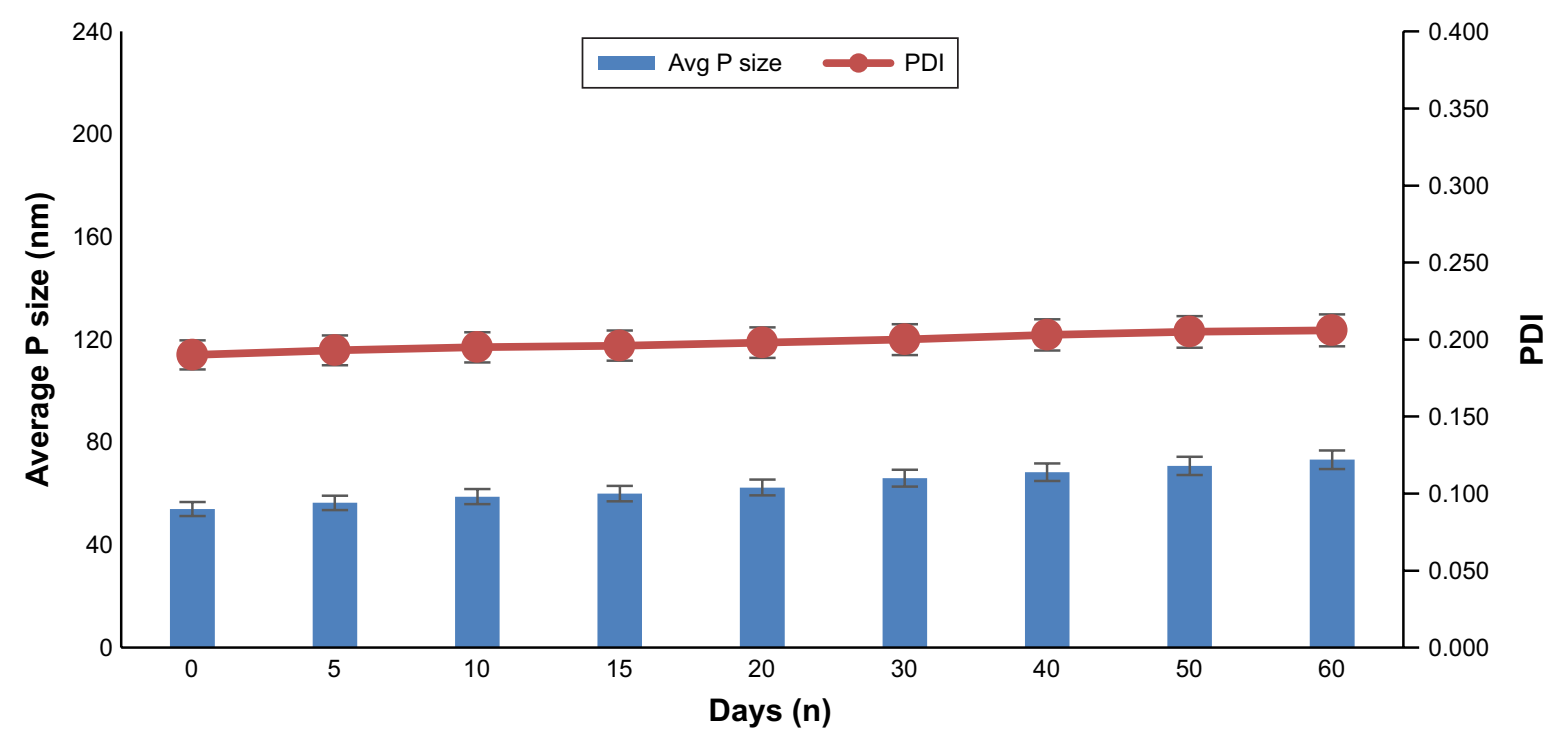

Figure 5 Stability studies of dexibuprofen nanoparticles at $>4^{\circ} \mathrm{C}$.

Abbreviation: PDI, polydispersity index.

sharp and high-intensity peaks (Figure 8). On the other hand, disappearance of some peaks and decrease in the intensity of the peaks as well were observed for nanocrystals. Owing to small particle size effect, the diffraction patterns are different compared to those of raw drug, as the peak intensity has been shifted to a lower level due to minor angle reflection by the nanocrystal. ${ }^{33}$

\section{Morphological studies}

SEM and TEM were used to study the morphology of raw and processed dexibuprofen. The SEM images (Figure 9A) showed that the raw drug was crystalline and triangular and irregular in shape. In addition, the images of nanocrystals obtained by TEM (Figure 9B) clearly showed that the nanoparticles had a homogenous size distribution with size $50 \mathrm{~nm}$ and also confirmed the crystalline nature.

\section{In vitro dissolution}

Investigation on the in vitro dissolution of the nanocrystals confirmed enhanced dissolution rate correlated to the raw and marketed tablets of dexibuprofen, that is, $200 \mathrm{mg}$. Figure 10 shows that $~ 85.4 \%$ of nanocrystals were dissolved in the first 5 minutes. On the other hand, raw dexibuprofen showed a dissolution rate of around $25.4 \%$ in the first 5 minutes, while marketed tablets showed around 35.6\%. This significant increase in dissolution rate of dexibuprofen nanocrystals indicated that controlled nucleation produced nanocrystals with increased surface area and,

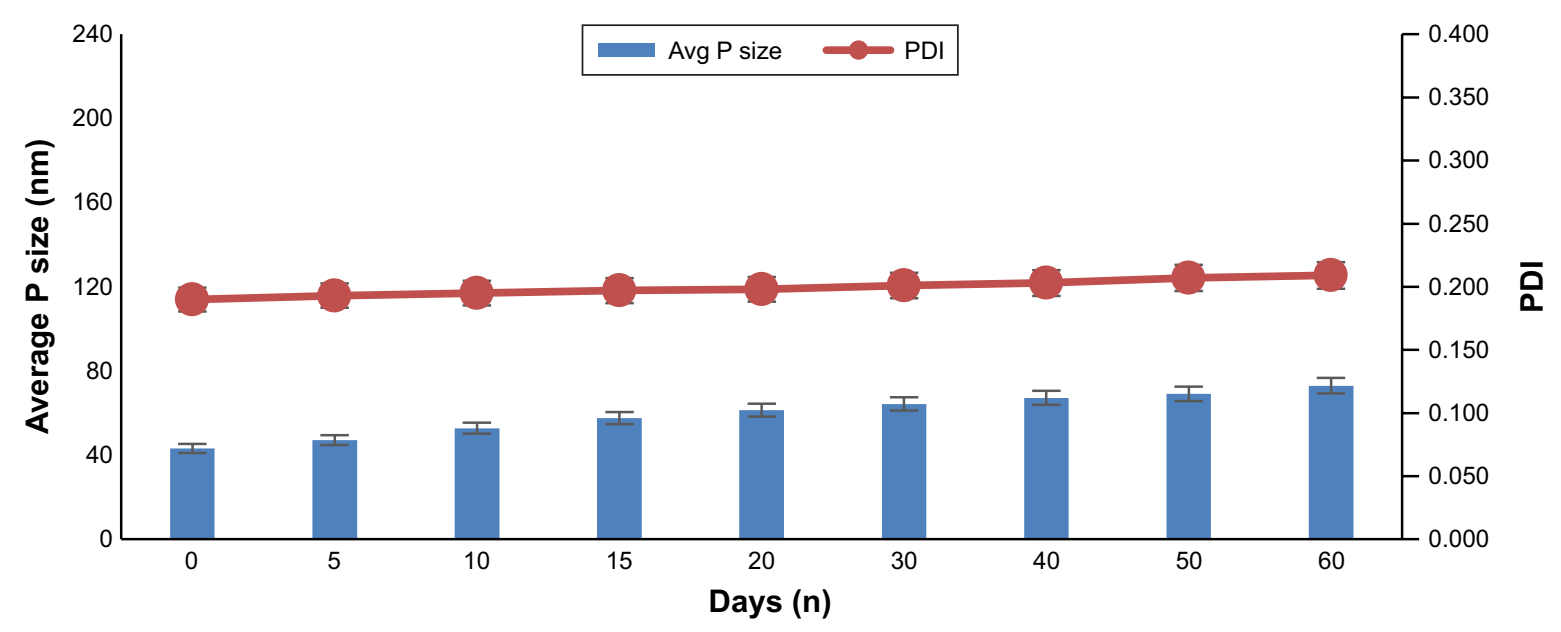

Figure 6 Stability studies of dexibuprofen nanoparticle at $>25^{\circ} \mathrm{C}$.

Abbreviation: PDI, polydispersity index. 


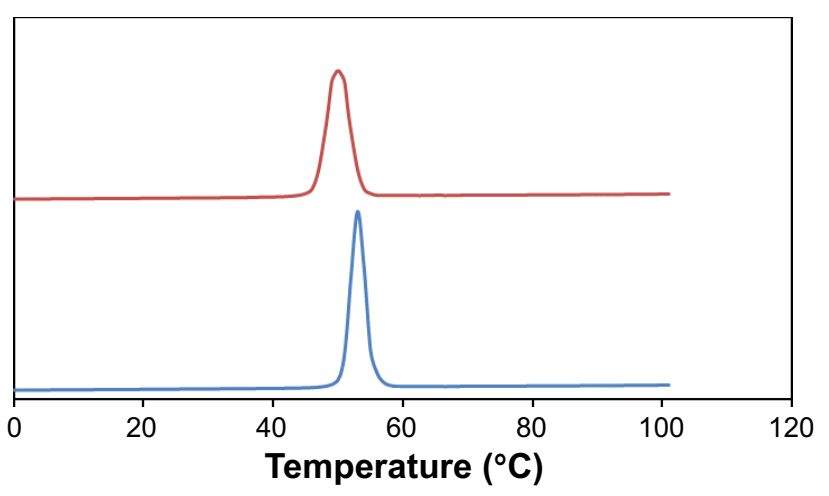

— Dexibuprofen raw — Dexibuprofen nanoparticle

Figure 7 DSC analysis of nanoparticles of dexibuprofen and their raw counterparts. Abbreviation: DSC, differential scanning calorimetry.

consequently, enhanced the dissolution rate. ${ }^{18}$ Moreover, it is already proved that as per the Ostwald-Freundlich equation, nanoparticles with a size below $100 \mathrm{~nm}$ have quicker dissolution rate. ${ }^{28}$

\section{Conclusion}

This study demonstrated that MCFR is a low-energy novel bottom-up technology which can potentially produce stable nanocrystals. However, the experimental and process conditions need to be properly controlled. The optimized process conditions including solvent, antisolvent flow rates, inlet angles, stirring rate and mixing time are the key factors that alter the particle size of the nanoparticles. High antisolvent flow rate, small inlet angle, high mixing time and stirring rate are the favorable factors to produce nanocrystals with a small particle size. Additionally, the appropriate selection of the polymers/surfactant and the low concentration of the drug are the key factors to control the particle size during nucleation. MCFR is a technology which produces the nanocrystals without changes in particle attributes, especially crystallinity of the particles. In future perspectives, this technology can potentially be scaled up. Also, the produced nanocrystals could be converted to the solid dosage form and

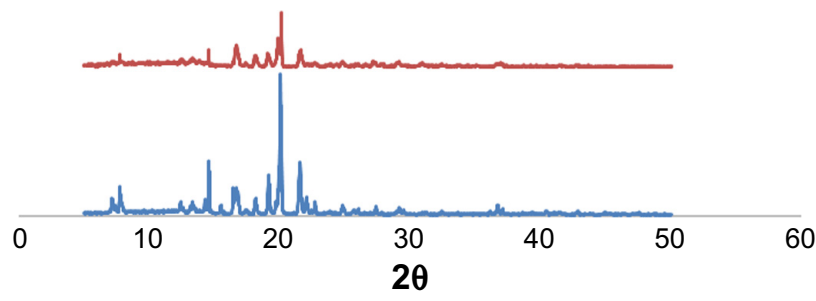

Dexibuprofen unprocessed - Dexibuprofen nanoparticle

Figure 8 X-ray diffractograms of nanoparticles of dexibuprofen and their raw counterparts.
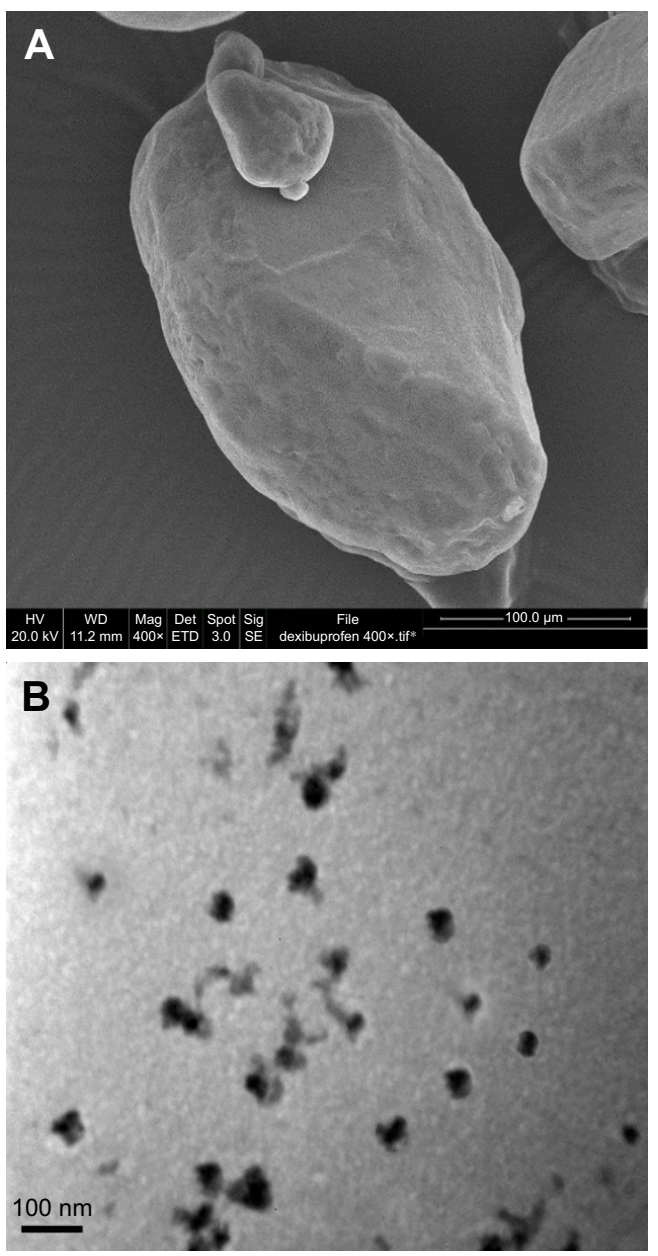

Figure 9 (A) SEM image of raw dexibuprofen and (B) TEM image of dexibuprofen nanoparticle.

Abbreviations: SEM, scanning electron microscopy; TEM, transmission electron microscopy.

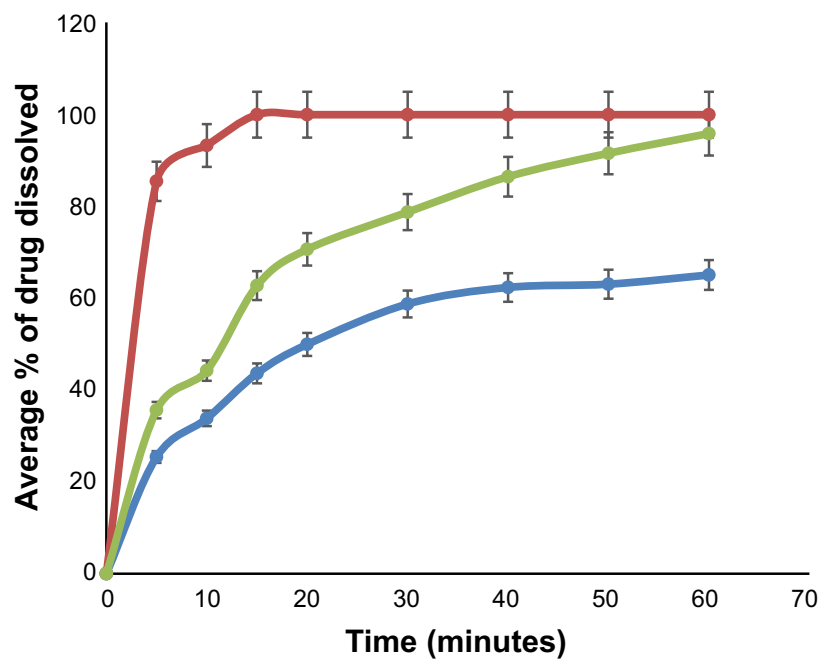

Average $\%$ of unprocessed dexibuprofen dissolved

Average \% of dexibuprofen nanosuspension dissolved Average \% of dexibuprofen tablet dissolved

Figure 10 Dissolution studies of raw counterparts, nanoparticles and marketed product of dexibuprofen. 
the process industrialized at a large scale by using chemical engineering approach.

\section{Acknowledgments}

Jahangir Khan appreciatively acknowledges the support of University of Malakand, HEC Pakistan for its support under the International Research support initiative program and the School of Pharmacy Institute of Life Sciences Research, University of Bradford, UK, for providing resources to accomplish research project.

\section{Author contributions}

We declare that this work was done by the authors named in this article and all liabilities pertaining to claims relating to the content of this article will be borne by the authors. All authors contributed toward data analysis, drafting and revising the paper and agree to be accountable for all aspects of the work.

\section{Disclosure}

The authors report no conflicts of interest in this work.

\section{References}

1. de Waard H, Hinrichs WL, Frijlink HW. A novel bottom-up process to produce drug nanocrystals: controlled crystallization during freezedrying. J Control Release. 2008;128(2):179-183.

2. Kawabata Y, Wada K, Nakatani M, Yamada S, Onoue S. Formulation design for poorly water-soluble drugs based on biopharmaceutics classification system: basic approaches and practical applications. Int $J$ Pharm. 2011;420(1):1-10.

3. Plakkot S, de Matas M, York P, Saunders M, Sulaiman B. Comminution of ibuprofen to produce nano-particles for rapid dissolution. Int $J$ Pharm. 2011;415(1-2):307-314.

4. Chen H, Khemtong C, Yang X, Chang X, Gao J. Nanonization strategies for poorly water-soluble drugs. Drug Discov Today. 2011;16(7-8): 354-360.

5. Serajuddin AT. Solid dispersion of poorly water-soluble drugs: early promises, subsequent problems, and recent breakthroughs. J Pharm Sci. 1999;88(10):1058-1066.

6. Schwarz C, Mehnert W, Lucks J, Müller R. Solid lipid nanoparticles (SLN) for controlled drug delivery. I. Production, characterization and sterilization. Journal of Controlled Release. 1994;30(1):83-96

7. Ghosh I, Bose S, Vippagunta R, Harmon F. Nanosuspension for improving the bioavailability of a poorly soluble drug and screening of stabilizing agents to inhibit crystal growth. Int J Pharm. 2011;409(1-2): 260-268.

8. Rabinow BE. Nanosuspensions in drug delivery. Nat Rev Drug Discov. 2004;3(9):785-796.

9. Kakran M, Sahoo NG, Li L, et al. Fabrication of drug nanoparticles by evaporative precipitation of nanosuspension. Int J Pharm. 2010; 383(1-2):285-292.

10. de Waard H, Frijlink HW, Hinrichs WL. Bottom-up preparation techniques for nanocrystals of lipophilic drugs. Pharm Res. 2011;28(5): $1220-1223$.

11. Patravale VB, Date AA, Kulkarni RM. Nanosuspensions: a promising drug delivery strategy. J Pharm Pharmacol. 2004;56(7):827-840.

12. Hao H, Wang G, Sun J. Enantioselective pharmacokinetics of ibuprofen and involved mechanisms. Drug Metab Rev. 2005;37(1):215-234.
13. Ibuprofen KC. Dexibuprofen: the superior non-steroidal anti-inflammatory agents for development of pharmaceuticals. Int J Curr Pharm Res. 2010;2:1-3.

14. Kaehler ST, Phleps W, Hesse E. Dexibuprofen: pharmacology, therapeutic uses and safety. Inflammopharmacology. 2003;11(4):371-383.

15. Abdelbary G, Makhlouf A. Adoption of polymeric micelles to enhance the oral bioavailability of dexibuprofen: formulation, in-vitro evaluation and in-vivo pharmacokinetic study in healthy human volunteers. Pharm Dev Technol. 2014;19(6):717-727.

16. van der Woerd M, Ferree D, Pusey M. The promise of macromolecular crystallization in microfluidic chips. J Struct Biol. 2003;142(1): $180-187$.

17. Ali HS, York P, Blagden N. Preparation of hydrocortisone nanosuspension through a bottom-up nanoprecipitation technique using microfluidic reactors. Int J Pharm. 2009;375(1-2):107-113.

18. Khan S, Matas MDE, Zhang J, Anwar J. Nanocrystal preparation: lowenergy precipitation method revisited. Cryst Growth Des. 2013;13(7): 2766-2777.

19. Rao Y, Kumar M, Apte S. Formulation of nanosuspensions of albendazole for oral administration. Curr Nanosci. 2008;4(1):53-58.

20. Shah SM, Ullah F, Khan S, et al. Smart nanocrystals of artemether: fabrication, characterization, and comparative in vitro and in vivo antimalarial evaluation. Drug Des Devel Ther. 2016;10:3837-3850.

21. Jahangir Khan SB, Shahzeb K, Ayesha I, et al. Fabrication and characterization of dexibuprofen nanocrystals using DENA ${ }^{\circledR}$ media milling. Lat Am J Pharm. 2018;37(5):947-952.

22. Y-F S, Kim H, Kovenklioglu S, Lee W. Continuous nanoparticle production by microfluidic-based emulsion, mixing and crystallization. J Solid State Chem. 2007;180(9):2625-2629.

23. Zhao H, Wang J-X, Wang Q-A, Chen J-F, Yun J. Controlled liquid antisolvent precipitation of hydrophobic pharmaceutical nanoparticles in a microchannel reactor. Ind Eng Chem Res. 2007;46(24):8229-8235.

24. Zhang S, Yun J, Shen S, et al. Formation of solid lipid nanoparticles in a microchannel system with a cross-shaped junction. Chem Eng Sci. 2008;63(23):5600-5605.

25. Zhang H-X, Wang J-X, Shao L, Chen J-F. Microfluidic fabrication of monodispersed pharmaceutical colloidal spheres of atorvastatin calcium with tunable sizes. Ind Eng Chem Res. 2010;49(9):4156-4161.

26. Brook TL. Design and Fabrication of a Novel Microfluidic Crystalliser for Organic Nanoparticle Production: Investigation of Process Parameters on the Production of Salicylic Acid Nanoparticles for Optimised Drug Delivery. University of Bradford; 2006.

27. Matteucci ME, Hotze MA, Johnston KP, Williams RO. Drug nanoparticles by antisolvent precipitation: mixing energy versus surfactant stabilization. Langmuir. 2006;22(21):8951-8959.

28. Müller RH, Peters K. Nanosuspensions for the formulation of poorly soluble drugs: I. Preparation by a size-reduction technique. Int J Pharm. 1998;160(2):229-237.

29. O’Mahony M, Leung AK, Ferguson S, Trout BL, Myerson AS. A process for the formation of nanocrystals of active pharmaceutical ingredients with poor aqueous solubility in a nanoporous substrate. Org Process Res Dev. 2015;19(9):1109-1118.

30. Ali HS, York P, Ali AM, Blagden N. Hydrocortisone nanosuspensions for ophthalmic delivery: a comparative study between microfluidic nanoprecipitation and wet milling. $J$ Control Release. 2011;149(2): $175-181$.

31. Freitas C, Müller RH. Effect of light and temperature on zeta potential and physical stability in solid lipid nanoparticle (SLN $\left.{ }^{\mathrm{TM}}\right)$ dispersions. Int J Pharm. 1998;168(2):221-229.

32. Patravale VB, Date AA, Kulkarni RM. Nanosuspensions: a promising drug delivery strategy. J Pharm Pharmacol. 2004;56(7):827-840.

33. Bunjes H, Koch MHJ, Westesen K. Effect of particle size on colloidal solid triglycerides. Langmuir. 2000;16(12):5234-5241.

34. Deng J, Huang L, Liu F. Understanding the structure and stability of paclitaxel nanocrystals. Int J Pharm. 2010;390:242-249. 


\section{Publish your work in this journal}

Drug Design, Development and Therapy is an international, peerreviewed open-access journal that spans the spectrum of drug design and development through to clinical applications. Clinical outcomes, patient safety, and programs for the development and effective, safe, and sustained use of medicines are the features of the journal, which

has also been accepted for indexing on PubMed Central. The manuscript management system is completely online and includes a very quick and fair peer-review system, which is all easy to use. Visit http://www.dovepress.com/testimonials.php to read real quotes from published authors.

Submit your manuscript here: http://www.dovepress.com/drug-design-development-and-therapy-journal 